\title{
Preparation and certification of carbon monoxide gas reference material for the quality of $\mathrm{CO}$ emission measurements
}

\author{
Adel. B. Shehata $\oplus^{*}$, Najjy H. Alyami $\odot$, Abdullah S. Alowaysi $\odot$ and \\ Abdulrahman. R. Alaskar
}

Saudi Standards, Metrology and Quality Org./National Measurement and Calibration Center

(SASO/NMCC), P. O. Box 3437 Riyadh 11471 KSA

(Received April 27, 2021; Revised May 21, 2021; Accepted May 25, 2021)

\begin{abstract}
Carbon monoxide emissions in air are toxic and its monitoring is of great concern worldwide. The monitoring activities should rely on traceable measurement results to the SI units. To serve this monitoring purpose in Saudi Arabia, a primary gas mixture $(200 \mathrm{mmol} / \mathrm{mol})$ of Carbon monoxide $(\mathrm{CO})$ in nitrogen has been gravimetrically prepared from pure $\mathrm{CO}$ and pure $\mathrm{N}_{2}$ in $5 \mathrm{~L}$ aluminum gas cylinder based on ISO 6142. From this mixture, three diluted mixtures of concentrations $4.99,7.49$ and $10.01 \mathrm{mmol} / \mathrm{mol}$ were prepared also in $5 \mathrm{~L}$ cylinders and the uncertainty of these gravimetric preparations was calculated. The mole fractions of the three mixtures were verified by GC-TCD in accordance with ISO 6143 and the uncertainty of the chromatographic measurements was calculated. The gravimetrically and chromatographically measured mole fractions together with their standard uncertainties were found compatible indicating good quality of the produced primary gas mixtures. Long term stability of the three gas mixtures was monitored along four years, and the results obtained showed very good stability of the gas mixtures. The relative uncertainty of the GC analytical results was found $0.52 \%, 0.51 \%$ and $0.52 \%$ which is small enough and advantageous for the calibration of $\mathrm{CO}$ emission measuring equipment.
\end{abstract}

Keywords: CO; $\mathrm{N}_{2}$; weighing; GC-TCD; uncertainty; stability. (C) 2021ACG Publications. All rights reserved.

\section{Introduction}

Carbon monoxide gas is considered one of the dangerous toxic pollutants that exist in air as emissions mainly from cars and vehicles and as a result, the $\mathrm{CO}$ monitoring has received great attention worldwide and binding regulations have been developed to set the safe limits in air [1-4]. These regulations are evaluated from time to time and therefore, environmental monitoring data that are collected by measuring devices is very important for evaluation of the environmental situation in every country. Since gas analysis is an important branch of chemical measurements and has crucial environmental and health applications, it has become inevitable that measurement results are traceable to the SI units and uncertainty of measurements is properly estimated to judge the traceability [5]. This creates a strong need for primary gas mixtures produced by reliable methods to be used in the calibration of $\mathrm{CO}$ gas measuring instruments through an unbroken chain of calibrations [6-8]. There are several

\footnotetext{
* Corresponding author: E-Mail: adelshehata63@yahoo.com ; a.shehata@saso.gov.sa
} 
methods for the preparation of gas mixtures, including gravimetric, barometric, volumetric and dynamic [9-11]. The gravimetric method is the most widely used because it has high accuracy since a very small mass of a gas component can be added into the cylinder with small uncertainty based on its molecular weight [12]. Details of this method are described in ISO 6142 [11] where the concentration of gas mixtures as a mole fraction depends on the mass of the filled gas, the molar mass and purity of the parent gases. The mass of each gas component added to the cylinder is to be calculated as the difference between the mass of the cylinder before and after filling. Accuracy of the prepared gas mixture depends on the accuracy of the weighing system, the filling device and quality of the cylinders used [12]. The gravimetric method is characterized by its small uncertainties and direct traceability to the SI units and the ability to prepare gas mixtures with a large scale of configuration. Uncertainty associated with the certified value must be evaluated accurately and all potential sources are taken into consideration to ensure reliability of the gas mixture certification process. The weighing process, purity of gases, and the molecular weight of each gas mixture component are the main sources of uncertainty. Other sources drawn from experience can also be considered and it is strongly required that uncertainty should be neither overestimated nor underestimated [13-15]. In Saudi Arabia, there is a need for locally produced CO gas mixtures traceable to the SI to support the $\mathrm{CO}$ emission monitoring. In this paper, a $200 \mathrm{mmol} / \mathrm{mol}$ primary gas mixture was prepared gravimetrically from pure $\mathrm{CO}$ and pure $\mathrm{N}_{2}$. From this mixture, three other mixtures of concentrations, $4.99,7.49$ and $10.01 \mathrm{mmol} / \mathrm{mol}$ were prepared by dilution in 5L cylinders as calibrants of $\mathrm{CO}$ measuring equipment. The uncertainties associated with these gravimetric preparations were calculated and the prepared mixtures were then verified by a calibrated GC-TCD with good repeatability of measurements. The gravimetric and chromatographic measured mole fractions $(\mathrm{mmol} / \mathrm{mol})$ and their standard uncertainties were found compatible indicating the validity of the gas mixture CRM certification.

\section{Materials and Methods}

\subsection{Pure Gases}

The CO $(99.5 \%)$ and the $\mathrm{N}_{2}(99.9999 \%)$ pure gases were supplied by Linda, the Netherlands. The aluminum alloy gas cylinders $(5 \mathrm{~L})$ to be filled with gas mixtures were purchased from Air Liquide, the Netherlands.

\subsection{The Evacuation System}

The evacuation system was manufactured and supplied by TÜBİTAK UME, Turkey. It was built up with a Pfeiffer pumping station and a manufactured manifold with maximum of six cylinderconnections by changing the existing valve locations.

\subsection{The Gas Filling Apparatus}

The gas filling apparatus model GFS1, was manufactured and supplied by TÜBITTAK UME, Turkey. This system is able to fill the cylinders in accordance with ISO 6142. All gas flow lines are electro-polished stainless steel and withstand pressure of 200 bars. It is connected with a turbomolecular pump and is capable of evacuation of all lines from gases down to a vacuum of less than $1 \times 10^{-6}$ mbar.

\subsection{The Automatic Weighing System}

The system shown in Figure S1 (see supporting information) was provided by TÜBİTAK UME, Turkey for automatic weighing of the gas mixture cylinders in comparison with a reference cylinder. The construction of the system was made from an anti-magnetic anodized aluminum material. The load bearing areas were strengthened by static and dynamic structures and the entire system was covered with unbreakable solid material. The system is equipped with a software capable to prepare gas mixtures gravimetrically according to ISO 6142 . 


\subsection{GC Conditions}

Gravimetrically prepared gas mixtures were analyzed using Agilent Technologies 7890B GC system equipped with TCD detector. An HP-Plot (19091P-S12 HP-AL/S) column (25 m $x 320$ $\mathrm{mm} x 8.0 \mu$ ) was used for the measurements. The injector and detector temperatures were adjusted to $250{ }^{\circ} \mathrm{C}$. The $\mathrm{GC}$ oven temperature started at $60^{\circ} \mathrm{C}$ (for $1 \mathrm{~min}$ ) and was ramped to $80{ }^{\circ} \mathrm{C}$ at $20^{\circ} \mathrm{C} / \mathrm{min}$ then to $200{ }^{\circ} \mathrm{C}$ at $30{ }^{\circ} \mathrm{C} / \mathrm{min}$ and the hold time was $1.33 \mathrm{~min}$. The total run time was $7 \mathrm{~min}$. Helium gas as a carrier has a flow rate of $2 \mathrm{~mL} / \mathrm{min}$ and the reference gas flow was used as $45 \mathrm{~mL} / \mathrm{min}$.

\subsection{The CO primary Gas Mixtures}

Carbon monoxide and nitrogen do not react with each other when mixed together and considerably lower concentrations of them are stable in aluminum cylinders [11]. A primary gas mixture (M1) of $\mathrm{CO}, 200 \mathrm{mmol} / \mathrm{mol}$ was prepared in a $5 \mathrm{~L}$ high pressure aluminum cylinder. From this mixture, three gas mixtures (M2-M4) of mole fractions, $x_{i}, 5,7.5$ and $10 \mathrm{mmol} / \mathrm{mol}$ were gravimetrically diluted. The target masses of $\mathrm{CO}$ and $\mathrm{N}_{2}$ components required to prepare these mixtures were calculated according to equation 1 .

where

$$
m_{i}=\frac{x_{i} \times p_{F} \times V_{c y l} \times M_{i}}{R \times T \times Z_{f}}
$$

$m_{i} \quad$ mass $(\mathrm{g})$ of $\mathrm{CO}$ or $\mathrm{N}_{2}$ in the mixture

$x_{i} \quad$ intended mole fraction $(\mathrm{mol} / \mathrm{mol})$ of $\mathrm{CO}$ or $\mathrm{N}_{2}$

$p_{\mathrm{f}} \quad$ filling pressure $(\mathrm{Pa})$ of the mixture

$V_{\text {cyl }} \quad$ volume $\left(\mathrm{m}^{3}\right)$ of the cylinder

$M_{i} \quad$ the molar mass of CO $(28.01 \mathrm{~g} / \mathrm{mol})$ and of nitrogen $\left(\mathrm{N}_{2}\right)(28.012 \mathrm{~g} / \mathrm{mol})$

$R \quad$ the gas constant $(8,31451 \mathrm{~J} / \mathrm{mol} . \mathrm{K})$

$T$ the temperature of filling in $\mathrm{K}$

$Z_{\mathrm{f}} \quad$ the compression factor of the mixture at $T$ and $p_{\mathrm{F}}$

\subsection{The Filling Process}

Each cylinder was evacuated firstly to get rid of any possible adsorbed gas impurities on the inner walls using the evacuation machine. Evacuation was continued for $24 \mathrm{~h}$ and the pressure was observed until vacuum reached 1.2-1.5 $\times 10^{-7}$ mbar. The evacuated cylinder was disconnected from the vacuum machine and after temperature equilibration, it was weighed empty against a reference empty cylinder of the same type and mass using the automatic weighing comparator.

Before filling the gas cylinders, leaks were checked by pressurizing the gas filling system and checking each connection by spraying a little bit of snoop. No bubbles were observed which means that no leak was there. The pure nitrogen cylinder was connected to the gas filling system then opened gently at $40 \mathrm{bar}$ to flush the connecting tubing with a beam of nitrogen six times at vacuum pressure of $1 \times 10^{-6}$ bar to make the effect of contamination negligible. After that, flushing was made once with CO to ensure that no $\mathrm{N}_{2}$ remains in the tubing connections. The first primary gas mixture (M1) cylinder to be filled was connected to the other terminal of the gas filling system and was placed on a calibrated balance to monitor the target mass of the delivered gas component. Then, the pure $\mathrm{CO}$ gas cylinder was connected to the gas filling system instead of the $\mathrm{N}_{2}$ cylinder and was opened at 35-40 bar. This pressure was remained higher than the pressure in the primary mixture cylinder to prevent $\mathrm{CO}$ re-entering the transfer line. The pure $\mathrm{CO}$ gas was allowed to transfer slowly to the primary mixture cylinder while watching the balance until the target mass has been transferred. Mixture cylinder was then closed and the pure CO cylinder was also closed then both cylinders were disconnected from the gas filling system. When temperature equilibration was reached, the primary mixture cylinder was reweighed five times until constant mass. Following to this, the pure nitrogen cylinder was connected to the filling system and opened gently at 40 bar and the connecting tubing was flushed four times then, the primary mixture cylinder was connected again to the gas filling system. Cylinder was opened at 100-120 bar to deliver nitrogen slowly until the target mass of nitrogen was complete. The filled primary mixture cylinder (M1) and the pure nitrogen 
cylinder were then closed and disconnected from the gas filling system. After temperature equilibration, the primary mixture cylinder was reweighed 5 times until constant mass then homogenized by rolling for 8 hours. The same filling procedure was repeated using the filled primary mixture cylinder (M1) as source of pure $\mathrm{CO}$ to fill each of the three diluted primary gas mixture (M2-M4). A schematic diagram of the prepared gas mixtures is shown in Figure S2.

The actual mass of $\mathrm{CO}$ delivered in each cylinder was calculated by subtracting mass of the empty cylinder from the mass of the cylinder plus CO. Meanwhile, the actual mass of $\mathrm{N}_{2}$ was calculated by subtracting mass of cylinder plus $\mathrm{CO}$ from the mass of cylinder plus mass of $\mathrm{CO}$ and $\mathrm{N}_{2}$ and the weighing results are recorded in Table1. Contents of each of the prepared primary mixtures were homogenized by rotating the cylinder using the homogenization system for eight hours.

Table 1. Weighing results of $\mathrm{CO}$ and $\mathrm{N}_{2}$ in the three primary gas mixtures (M2-M4)

\begin{tabular}{lcc}
\hline Gas Mixture & Mass of CO $(\mathbf{g})$ & ${\text { Mass of } \mathbf{N}_{2}(\mathbf{g})}$ \\
\hline $\mathrm{M} 2(5 \mathrm{mmol} / \mathrm{mol})$ & 27.23 & 525.25 \\
M3 $(7.5 \mathrm{mmol} / \mathrm{mol})$ & 18.80 & 482.03 \\
M4 $(10 \mathrm{mmol} / \mathrm{mol})$ & 29.29 & 554.34 \\
\hline
\end{tabular}

\section{Results and Discussion}

\subsection{Calculation of the Mole Fractions of the Pure CO and $N_{2}$ Gases}

The certificate of pure $\mathrm{CO}$ gas received from the manufacturer showed that the purity of $\mathrm{CO}$ is 99.5\% and the impurities present in it are $\mathrm{CO}_{2}, \mathrm{H}_{2}, \mathrm{O}_{2}$, THC $\left(\mathrm{CH}_{4}\right)$ and $\mathrm{H}_{2} \mathrm{O}$ in the limits: $<1 \mathrm{ppm},<1$ $\mathrm{ppm},<1 \mathrm{ppm}<3500 \mathrm{ppm}$ and $<5 \mathrm{ppm}$ respectively. On the other hand, the manufacturer certificate of pure $\mathrm{N}_{2}$ showed that the purity of $\mathrm{N}_{2}$ is $99.999 \%$ and the impurities present in it are $\mathrm{CO}, \mathrm{CO}_{2}$, THC $\left(\mathrm{CH}_{4}\right)$, $\mathrm{O}_{2}$ and $\mathrm{H}_{2} \mathrm{O}$ and their limits were $<0.5 \mathrm{ppm},<0.5 \mathrm{ppm},<0.5 \mathrm{ppm}<5 \mathrm{ppm}$ and $<2 \mathrm{ppm}$ respectively. To determine the concentration of these impurities, a low limit was set as 0 and the upper limit was set as the value stated in the certificate. Then the assigned concentration of each impurity was calculated in ppm by adding the lower limit and the upper limit then dividing by 2 [11]. The assigned concentration of each impurity in ppm was divided by 1000000 to convert to $\mathrm{mol} / \mathrm{mol}$ as shown in Tables 2 and 3 . The mole fraction of the pure $\mathrm{CO}$ and the pure $\mathrm{N}_{2}$ was then calculated using equation 2 in which $n$ is the number of impurities.

$$
\text { mol fractionon of pure } \mathrm{CO} \text { or } \mathrm{N}_{2}=1-\sum_{i=1}^{n} \text { mol fraction of impurities }
$$

\subsection{Calculation of the mole fractions in the primary gas mixtures (M1-M4)}

The mol fraction of pure $\mathrm{CO}$ and $\mathrm{N}_{2}$ added in the primary gas mixture cylinders during the gravimetric preparations was calculated using equation 3 . The results obtained are shown in Table 3 .

$$
x_{i}=\frac{\sum_{A=1}^{p}\left(\frac{x_{i, A} \cdot m_{A}}{\sum_{i=1}^{n} x_{i, A} \cdot M_{i}}\right)}{\sum_{A=1}^{p}\left(\frac{m_{A}}{\sum_{i=1}^{n} x_{i, A} \cdot M_{i}}\right)}
$$

where

$x_{i} \quad:$ the mole fraction of the component $i$ in the final mixture, $i=1, \ldots, n$

$P \quad:$ the total number of the parent gases

$n \quad:$ the total number of the components in the final mixture

$m_{A} \quad$ : the mass of the $\mathrm{CO}$ or $\mathrm{N}_{2}$ determined by weighing, $A=1, \ldots, P$

$M_{i} \quad$ : the molar mass of the component $i, i=1, \ldots, n$

$x_{i, A}:$ the mole fraction of the component $i, i=1, \ldots, n$, in parent gas $A, A=1, \ldots, P$ 
Table 2. The mole fraction of $\mathrm{CO}$ and $\mathrm{N}_{2}$ in the gravimetrically prepared primary gas mixtures

\begin{tabular}{ccc}
\hline Primary gas mixture & Gas component & Mol fraction $(\mathbf{m m o l} / \mathbf{m o l})$ \\
\hline M1 & $\mathrm{CO}$ & 199.39 \\
& $\mathrm{~N}_{2}$ & 800.60 \\
M2 & $\mathrm{CO}$ & 4.99 \\
& $\mathrm{~N}_{2}$ & 995.01 \\
$\mathrm{M} 3$ & $\mathrm{CO}$ & 7.49 \\
& $\mathrm{~N}_{2}$ & 992.51 \\
M4 & $\mathrm{CO}$ & 10.01 \\
& $\mathrm{~N}_{2}$ & 989.99 \\
\hline
\end{tabular}

\subsection{Uncertainty of the Gravimetric Preparation of Gas Mixtures}

The sources of uncertainty associated with the mole fraction of $\mathrm{CO}$ in the gravimetrically prepared gas mixtures were identified and explained in the fish bone diagram shown in Figure 3. These sources are: the mass of pure $\mathrm{CO}$ and $\mathrm{N}_{2}$ gases, the air bouncy effects and the residual nitrogen gas in the evacuated cylinder, the molar mass of $\mathrm{CO}$ and $\mathrm{N}_{2}$ gases, the purity of $\mathrm{CO}$ and $\mathrm{N}_{2}$ gases, and the mole of $\mathrm{CO}$ and $\mathrm{N}_{2}$ added to the final gas mixtures. An estimation of each of these uncertainty contributions has been made and the combined standard uncertainty of the mole fraction of the prepared $\mathrm{CO}$ gas mixture was calculated as explained below.

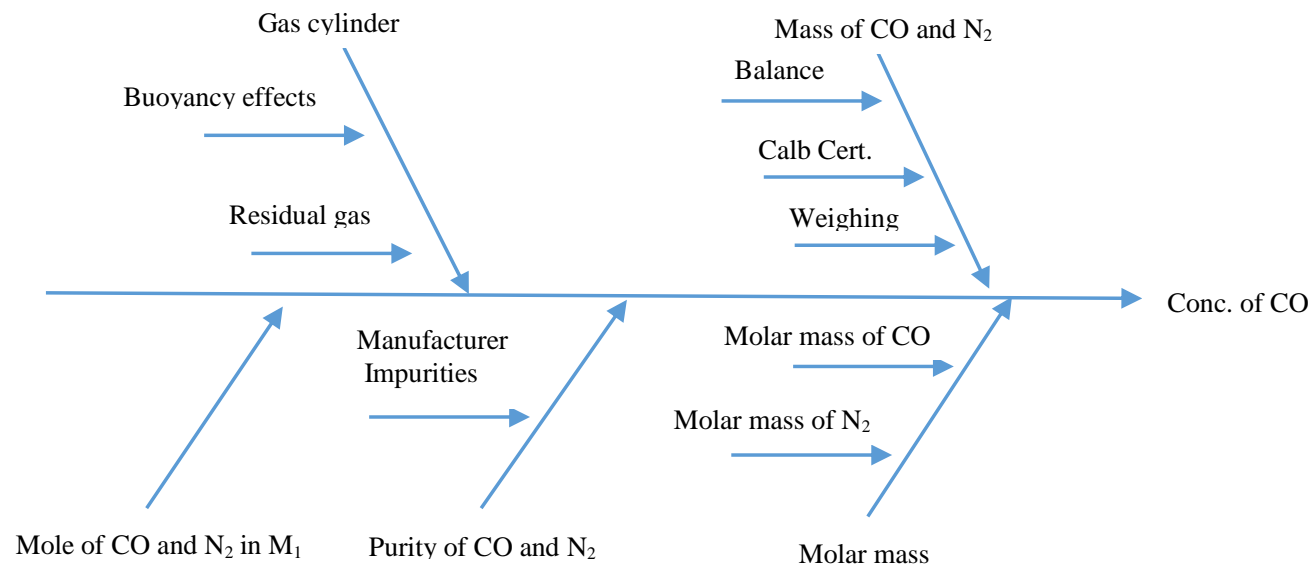

Figure 3. Fish bone diagram showing the sources of uncertainty in the gravimetric preparations

\subsubsection{The Mass of $\mathrm{CO}$ and $\mathrm{N}_{2}$ gases}

This source includes uncertainty of the weighing balance, calibration certificate of the balance, and weighing. The balance uncertainty resulted from the resolution, incorrect zero point, drift, and the position of the cylinder on the pan. This effect was evaluated by repeating the weighing of cylinder to be filled with the gas mixture 3 times. The pooled standard deviation $S_{p}$ of the repeated weighings was calculated using equation 4 in which $n_{1-3}$ is the number of measurements in each weighing process and $s_{1-3}$ is the standard deviation of each weighing process. The $S_{p}$ was divided by the square root of the number of weighing processes $(\sqrt{3})$ to obtain the standard uncertainty of the balance according to equation 5 .

$$
S_{p}=\sqrt{\frac{\left(n_{1}-1\right) s_{1}+\left(n_{2}-1\right) s_{2}+\left(n_{3}-1\right) s_{3}}{\left(n_{1}-1\right)+\left(n_{2}-1\right)+\left(n_{3}-1\right)}}
$$




$$
u_{\text {Balance }}=\frac{S_{p}}{\sqrt{n}}
$$

The calibration uncertainty of the weighing system was calculated using the function: $u=2.939 x$ $10^{-7} \times R$ given in the calibration certificate where $R$ can be substituted by the mass of the cylinder. The combined standard uncertainty, $u_{c}$ associated with the mass of $\mathrm{CO}$ and $\mathrm{N}_{2}$ gases from the balance, calibration certificate was calculated according to equations 6 and 7. The results obtained were 0.00008 and $0.000005 \mathrm{mg}$ for $\mathrm{CO}$ and $\mathrm{N}_{2}$ respectively.

$$
\begin{gathered}
u_{c} m(C O)=\sqrt{\left(u_{\text {Balance }}\right)^{2}+\left(u_{\text {Calb.Cert }}\right)^{2}} \\
u_{c} m\left(N_{2}\right)=\sqrt{\left(u_{\text {Balance }}\right)^{2}+\left(u_{\text {Calb.Cert }}\right)^{2}}
\end{gathered}
$$

In addition, the weighing uncertainty was estimated by weighing the gas mixture cylinder ( $\mathrm{S}$ ) in comparison to a reference cylinder (R) which is very close in mass in order to reduce the effect of air buoyancy. The weighing sequence was S-R-S-R-S-R-S-R-S and the weighing results were denoted from the first to the last weighing as: $\mathrm{C}_{0}-\mathrm{C} 1-\mathrm{C}_{2}-\mathrm{C}_{3}-\mathrm{C}_{4}-\mathrm{C}_{5}-\mathrm{C}_{6}-\mathrm{C}_{7}-\mathrm{C}_{8}$. The weight differences were calculated as: $\mathrm{C}_{0}-\mathrm{C}_{1}, \mathrm{C}_{2}-\mathrm{C}_{1}, \mathrm{C}_{2}-\mathrm{C}_{3}, \mathrm{C}_{4}-\mathrm{C}_{3}, \mathrm{C}_{4}-\mathrm{C}_{5}, \mathrm{C}_{6}-\mathrm{C}_{5}, \mathrm{C}_{6}-\mathrm{C}_{7}$, and $\mathrm{C}_{8}-\mathrm{C}_{7}$. The average of these 8 weighings was found $29515.75 \mathrm{mg}$ and the standard deviation was 0.89 which was divided by $\sqrt{8}$ to obtain the standard uncertainty of the weighing process as $0.315 \mathrm{mg}$.

\subsubsection{The Gas Cylinder}

\subsubsection{Air Buoyancy}

Although the gas mixture cylinder and the reference cylinder were chosen from the same batch, there are slight differences in the volume of the two cylinders $(5 \mathrm{~L}, 4.986 \mathrm{~L})$. This volume difference can give a mass difference between the two cylinders due to the variation in air density during the sequence weighing and this is known as air bouncy [16]. The air density in the automatic balance room changes due to the change in temperature, humidity and air pressure inside it [11]. These environmental conditions were measured during weighing and used to calculate the air density according to equation 8 .

$$
\rho_{a}=\frac{0.34848 p-0.009(h r) x \exp (0.061 t)}{273.15+t}
$$

where,

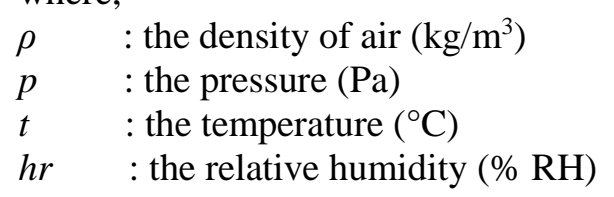

In the weighing process, we noticed that the largest difference in air density $(\Delta \rho)$ due to the change in temperature, humidity and pressure was $0.011 \mathrm{~kg} / \mathrm{m}^{3}$. This value was multiplied by the volume difference between the mixture cylinder $\left(V_{S}\right)$ and the reference cylinder $\left(V_{R}\right)$ to obtain the uncertainty due to air buoyancy, $u_{B}$ using equation 9 [16]. The calculated value was found 0.00015 for which a rectangular distribution was assumed and therefore it was divided by $\sqrt{3}$ to obtain the standard $u_{B}$ uncertainty, $0.00009 \mathrm{mg}$.

$$
u_{B}=\Delta \rho_{a}\left(V_{S}-V_{R}\right)
$$




\subsubsection{Residual Gas}

Before use, the cylinder was purged with nitrogen gas and then evacuated at a pressure of $10^{-7}$ mbar. It is assumed that the residual nitrogen pressure after vacuum is 0.1 bar [11]. The mass of this remaining residue can be calculated by multiplying 0.1 bar by volume of the cylinder (5L) and the density of nitrogen $(1.25 \mathrm{~g} / \mathrm{L})$. The calculated uncertainty value was found $0.625 \mathrm{mg}$ which was assumed to have a rectangular distribution, and therefore was divided by $\sqrt{3}$ to obtain the standard uncertainty as $3.29 \mathrm{mg}$.

\subsubsection{Purity of $\mathrm{CO}$ and $\mathrm{N}_{2}$}

The assigned concentration ( $\mathrm{mol} / \mathrm{mol}$ ) of impurities in $\mathrm{CO}$ listed in Tables 3 and those in $\mathrm{N}_{2}$ listed in Table 4 were divided by $\sqrt{ } 3$ to obtain their standard uncertainties. The uncertainty associated with the purity of $\mathrm{CO}$ and $\mathrm{N}_{2}$ gases was calculated by taking the square root of the summation of squares of the uncertainties of these impurities according to Equations No. 10 and 11 respectively.

Table 3. Impurity uncertainties associated with pure $\mathrm{CO}$ gas

\begin{tabular}{c|cccccc}
\hline $\begin{array}{c}\text { Gas } \\
\text { component }\end{array}$ & $\begin{array}{c}\text { Manufacturer } \\
\text { specification }\end{array}$ & $\begin{array}{c}\text { Low } \\
\text { limit }\end{array}$ & $\begin{array}{c}\text { High } \\
\text { limit }\end{array}$ & $\begin{array}{c}\text { Assigned } \\
\text { Conc }(\mathbf{p p m})\end{array}$ & $\begin{array}{c}\text { Conc } \\
(\mathbf{m o l} / \mathbf{m o l})\end{array}$ & $\begin{array}{c}\text { Uncertainty } \\
(\mathbf{m o l} / \mathbf{m o l})\end{array}$ \\
\hline $\mathrm{CO}_{2}$ & $<1 \mathrm{ppm}$ & 0 & 1 & 0.5 & 0.0000005 & 0.0000003 \\
$\mathrm{H}_{2}$ & $<1 \mathrm{ppm}$ & 0 & 1 & 0.5 & 0.0000005 & 0.0000003 \\
$\mathrm{O}_{2}$ & $<1 \mathrm{ppm}$ & 0 & 1 & 0.5 & 0.0000005 & 0.0000003 \\
$\mathrm{THC}\left(\mathrm{CH}_{4}\right)$ & $<3500 \mathrm{ppm}$ & 0 & 3500 & 1750 & 0.00175 & 0.001 \\
$\mathrm{H}_{2} \mathrm{O}$ & $<5 \mathrm{ppm}$ & 0 & 5 & 2.5 & 0.0000025 & 0.000001 \\
\hline
\end{tabular}

Table 4. Impurity uncertainties associated with pure $\mathrm{N}_{2}$ gas

\begin{tabular}{ccccccc}
\hline $\begin{array}{c}\text { Gas } \\
\text { component }\end{array}$ & $\begin{array}{c}\text { Manufacturer } \\
\text { specification }\end{array}$ & $\begin{array}{c}\text { Low } \\
\text { limit }\end{array}$ & $\begin{array}{c}\text { High } \\
\text { limit }\end{array}$ & $\begin{array}{c}\text { Assigned } \\
\text { Conc }(\mathbf{p p m})\end{array}$ & $\begin{array}{c}\text { Conc } \\
(\mathbf{m o l} / \mathbf{m o l})\end{array}$ & $\begin{array}{c}\text { Uncertainty } \\
(\mathbf{m o l} / \mathbf{m o l})\end{array}$ \\
\hline $\mathrm{CO}$ & $<0.5 \mathrm{ppm}$ & 0 & 0.5 & 0.25 & 0.00000025 & 0.00000014 \\
$\mathrm{CO}_{2}$ & $<0.5 \mathrm{ppm}$ & 0 & 0.5 & 0.25 & 0.00000025 & 0.00000014 \\
$\mathrm{THC}\left(\mathrm{CH}_{4}\right)$ & $<0.5 \mathrm{ppm}$ & 0 & 0.5 & 0.25 & 0.00000025 & 0.00000014 \\
$\mathrm{O}_{2}$ & $<5 \mathrm{ppm}$ & 0 & 5 & 2.5 & 0.0000025 & 0.0000014 \\
$\mathrm{H}_{2} \mathrm{O}$ & $<2 \mathrm{ppm}$ & 0 & 2 & 1 & 0.000001 & 0.0000006 \\
\hline
\end{tabular}

The obtained uncertainty values were found $0.001 \mathrm{~mol} / \mathrm{mol}$ for $\mathrm{CO}$ and $0.0000016 \mathrm{~mol} / \mathrm{mol}$ for $\mathrm{N}_{2}$

$$
\begin{aligned}
& u_{\text {impurity } \mathrm{CO}}=\sqrt{\left(\mathrm{CO}_{2}\right)^{2}+\left(\mathrm{H}_{2}\right)^{2}+\left(\mathrm{O}_{2}\right)^{2}+\left(\mathrm{CH}_{4}\right)^{2}+\left(\mathrm{H}_{2} \mathrm{O}\right)^{2}} \\
& u_{\text {impurity } \mathrm{N}_{2}}=\sqrt{(\mathrm{CO})^{2}+\left(\mathrm{CO}_{2}\right)^{2}+\left(\mathrm{CH}_{4}\right)^{2}+\left(\mathrm{O}_{2}\right)^{2}+\left(\mathrm{H}_{2} \mathrm{O}\right)^{2}}
\end{aligned}
$$

\subsubsection{Molar mass of $\mathrm{CO}$ and $\mathrm{N}_{2}$}

The atomic weights of $\mathrm{C}, \mathrm{O}$ and $\mathrm{N}$ elements and their associated uncertainties issued by IUPAC [17] are shown in Table 5. The molar uncertainty of $\mathrm{CO}\left(u_{M C O}\right)$ was calculated by combining uncertainty of $\mathrm{C}$ and $\mathrm{O}$ as shown in equation 12 , and uncertainty of the molar mass of $\mathrm{N}_{2}\left(u_{M N 2}\right)$ was calculated by equation 13 [18]. The results obtained were found 0.0005 and $0.00014 \mathrm{~g} / \mathrm{mol}$ respectively (Table 5).

$$
\begin{aligned}
& u_{M C O}=\sqrt{\left(u_{C}\right)^{2}+\left(u_{O}\right)^{2}} \\
& u_{M N_{2}}=\sqrt{2 x\left(u_{N}\right)^{2}}
\end{aligned}
$$


Table 5. IUPAC atomic weights of elements and their uncertainties

\begin{tabular}{cccc}
\hline Element & Atomic weight & Uncertainty & Standard uncertainty \\
\hline C & 12.0107 & 0.00080 & 0.00046 \\
H & 1.00794 & 0.00007 & 0.00004 \\
O & 15.9994 & 0.00030 & 0.00017 \\
N & 14.00307 & 0.00017 & 0.00010 \\
\hline
\end{tabular}

\subsubsection{Moles of $\mathrm{CO}$ and $\mathrm{N}_{2}$ Added to the Final Gas mixtures}

Since the number of moles equals mass divided by molecular weight $(n=m / M)$, the uncertainty of the mole fraction of $\mathrm{CO}$ and $\mathrm{N}_{2}$ pure gases added to the final gas mixtures was influenced by the uncertainty of the mass and molar mass of $\mathrm{CO}$ and $\mathrm{N}_{2}$. These uncertainties were calculated according to equations 14 and 15 and the obtained values were 0.000004 and $0.000004 \mathrm{~mol} / \mathrm{mol}$ for $\mathrm{CO}$ and $\mathrm{N}_{2}$ respectively.

$$
\begin{gathered}
u_{\text {mol of } C O}=n \text { of } C O \sqrt{\left(\frac{u_{m_{C O}}}{m_{C O}}\right)^{2}+\left(\frac{u_{M}}{M_{C O}}\right)^{2}} \\
u_{\text {mol of } N_{2}}=n \text { of } N_{2} \sqrt{\left(\frac{u_{m_{N_{2}}}}{m_{N_{2}}}\right)^{2}+2 x\left(\frac{u_{M}}{M_{N}}\right)^{2}}
\end{gathered}
$$

The combined standard uncertainty was calculated using equation 16 and was found 0.01 $\mathrm{mmol} / \mathrm{mol}$

$$
u_{c}=n C O \sqrt{\left(\frac{u_{m}}{\text { mass }}\right)^{2}+\left(\frac{u_{C y l}}{m_{C y l}}\right)^{2}+\left(\frac{u_{\text {purity }}}{\text { purity }}\right)^{2}+\left(\frac{u_{M \text { mass }}}{\text { Molar mass }}\right)^{2}+\left(\frac{u_{m o l} M_{1}}{m_{\text {ol }} M_{1}}\right)^{2}}
$$

\begin{tabular}{|c|c|c|c|c|c|c|}
\hline \multicolumn{2}{|c|}{ Source of uncertainty } & $(\mathbf{X})$ & $\mathbf{u}(\mathbf{x})$ & Unit & $\mathbf{u}(\mathbf{x}) / \mathbf{X}$ & $\mathbf{u}_{\mathbf{c}}$ \\
\hline \multirow{2}{*}{ Mass of $\mathrm{CO}$} & Balance & 29.29 & 0.0005 & $\mathrm{mg}$ & 0.00002 & \multirow{2}{*}{0.00008} \\
\hline & Cal. Cert & 29.29 & 0.002 & $\mathrm{mg}$ & 0.00008 & \\
\hline \multirow{2}{*}{ Mass of $\mathrm{N}_{2}$} & Balance & 554.34 & 0.0005 & $\mathrm{mg}$ & 0.000001 & \multirow{2}{*}{0.000005} \\
\hline & Cal. Cert & 554.34 & 0.003 & $\mathrm{mg}$ & 0.000005 & \\
\hline Weighing & & 29515.75 & 0.315 & $\mathrm{mg}$ & 0.00001 & \\
\hline \multirow{2}{*}{ Gas cylinder } & $\begin{array}{c}\text { Buoyancy } \\
\text { effects }\end{array}$ & 8018.75 & 0.0001 & $\mathrm{mg}$ & 0.00000001 & \multirow[t]{2}{*}{0.0004} \\
\hline & $\begin{array}{l}\text { Residual } \\
\text { gas }\end{array}$ & 8018.75 & 3.29 & $\mathrm{mg}$ & 0.0004 & \\
\hline Purity of $\mathrm{CO}$ & & 0.99825 & 0.001 & $\mathrm{~mol} / \mathrm{mol}$ & 0.001 & \\
\hline Purity of $\mathrm{N}_{2}$ & & 0.999996 & 0.000002 & & 0.000002 & 0.001 \\
\hline Molar mass of & $\mathrm{CO}$ & 28.01 & 0.0005 & $\mathrm{~g} / \mathrm{mol}$ & 0.00002 & \\
\hline Molar mass of & $\mathrm{N}_{2}$ & 28.01 & 0.0001 & $\mathrm{~g} / \mathrm{mol}$ & 0.000005 & 0.000018 \\
\hline mole of $\mathrm{CO}$ & & 0.19939 & 0.000004 & mol & 0.00002 & \\
\hline Mole of $\mathrm{N}_{2}$ & & 0.80060 & 0.000004 & mol & 0.000005 & 0.000018 \\
\hline $\mathrm{u}_{\mathrm{c}}$ & & \multicolumn{5}{|c|}{0.001} \\
\hline \multicolumn{3}{|c|}{ Conc. (mmol/mol) } & \multicolumn{3}{|c|}{10.0} & \\
\hline \multicolumn{3}{|c|}{$\mathrm{u}_{\mathrm{c}} x$ Conc $(\mathrm{mmol} / \mathrm{mol})$} & \multicolumn{3}{|c|}{0.01} & \\
\hline
\end{tabular}

Table 6. Gravimetric uncertainty components of the mol fraction of M4 as an example 
All the calculated values were listed in Table 6 which shows a full uncertainty budget for gas mixture 4 (M4) as an explanatory example. Uncertainty of the other two mixtures was estimated by the same approach and the results are given in Table 9.

\subsection{Verification of Primary Mixtures Concentration by GC-TCD}

In order to verify the mole fractions of the three gravimetrically prepared gas mixtures (M2-M4), they were measured by GC-TCD under the chromatographic conditions explained above [19]. To ensure traceability of the measurement results to the SI units, five CRMs produced by the Turkish Institute of Metrology (UME) were used for calibration of the GC-TCD every day of measurement. Their concentrations were selected as: $0.00075,0.0025,0.005,0.0075$ and $0.015 \mathrm{~mol} / \mathrm{mol}$ to bracket the concentrations of the prepared gas mixtures which are: $0.0049,0.0075$, and $0.01 \mathrm{~mol} / \mathrm{mol}$. In the analysis, the CRMs (R) and the gas mixture samples (S) were injected in an ascending mole fraction order in the following sequence: R-S-R-S-R-S-R-R. Figure 4(a) shows a typical GC-TCD chromatogram in which the nitrogen peak appeared at retention time $2.65 \mathrm{~min}$ and the CO peak appeared at $5.17 \mathrm{~min}$. Each CRM was injected 5 times and the average peak areas were: 33.907, 113.915, 228.278, 341.595 and 518.345 respectively. They were plotted against the corresponding CRMs mole fractions to obtain the calibration curve shown in Figure 4(b) which has a linear equation: $y=45104 x+1.3872$ and $R^{2}$ equals 0.9999 . Each gas mixture sample was injected 10 times under reproducibility conditions and the obtained peak areas together with mean are shown in Table 7. The standard uncertainty, $u\left(y_{i}\right)$ was calculated according to ISO 6143 using equation 17 in which $y_{i}$ is the mean and $y_{i j}$ is the individual determination. The RSD\% was also calculated and recorded in Table 7 [19]. One can note that the calculated RSD\% is very small indicating a good precision of the measurement results. To calculate the mol fraction of $\mathrm{CO}$ in each of the three gas mixtures, the corresponding average peak area was substituted in the linear equation and the obtained results were $4.98,7.5$ and $10 \mathrm{mmol} / \mathrm{mol}$ respectively.

$$
u\left(y_{i}\right)=\frac{1}{\sqrt{90}} \sqrt{\sum_{j=1}^{10}\left(y_{i j}-y_{i}\right)^{2}}
$$
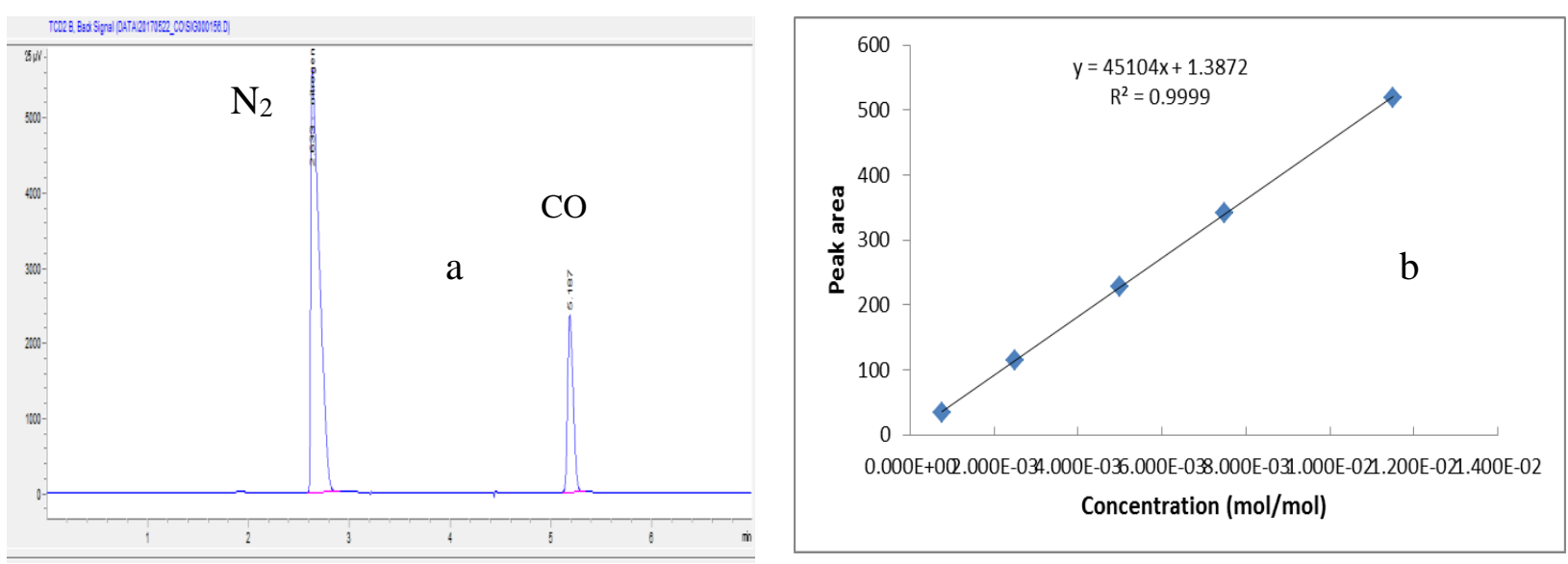

Figure 4. Typical GC-TCD chromatogram (a) and GC-TCD calibration curve (b) 
Table 7. Peak areas of $\mathrm{CO}$ in the three primary gas mixtures (M2-M4)

\begin{tabular}{c|ccc}
\hline & M2 & M3 & M4 \\
\hline \multirow{5}{*}{ Peak area } & 226.88 & 341.69 & 454.86 \\
& 226.93 & 341.78 & 454.74 \\
& 226.92 & 341.87 & 454.84 \\
& 226.97 & 341.78 & 454.88 \\
& 227.02 & 341.88 & 454.81 \\
& 227.06 & 341.72 & 454.94 \\
& 227.02 & 341.84 & 455.00 \\
& 227.11 & 341.76 & 455.22 \\
Mean & 227.11 & 341.66 & 455.56 \\
$u\left(y_{i}\right)$ & 227.10 & 341.65 & 455.79 \\
\hline$R S D$ & 227.01 & 341.76 & 455.06 \\
& 0.026 & 0.027 & 0.12 \\
& 0.011 & 0.008 & 0.026 \\
\hline
\end{tabular}

\subsection{Uncertainty of the Chromatographic Verification of the Mole Fractions of Gas Mixtures}

Uncertainty of the GC measurement results was identified from four sources which are: mass of $\mathrm{CO}$ (gravimetry), conc. of CRMs, peak area of the 5 CRMs used for calibration $(P A)$ and peak area of the gas mixture sample (PA Sample).

Table 8. Uncertainty components of the GC-TCD measurements of M4 as an example.

\begin{tabular}{c|llll}
\hline Source of uncertainty & $\mathbf{X}$ & $\mathbf{u}(\mathbf{X})$ & Unit & $\mathbf{u}(\mathbf{X}) / \mathbf{X}$ \\
\hline Mass of CO & 29.29 & 0.00001 & $\mathrm{~g}$ & 0.0000003 \\
\hline & 0.00075 & 0.0000008 & & 0.001 \\
CRM & 0.0025 & 0.000003 & & 0.001 \\
& 0.004999 & 0.000005 & $\mathrm{~mol} / \mathrm{mol}$ & 0.001 \\
& 0.0075 & 0.000008 & & 0.001 \\
& 0.01 & 0.00001 & & 0.001 \\
\hline & & $u_{c} \mathrm{CRM}$ & & 0.002 \\
\hline & 33.91 & 0.036 & & 0.001 \\
Peak Area $(\mathrm{R})$ & 113.91 & 0.01 & & 0.0001 \\
& 228.28 & 0.05 & $\mathrm{~mm}^{2}$ & 0.0002 \\
& 341.60 & 0.056 & & 0.0002 \\
& 454.59 & 0.24 & & 0.0005 \\
\hline Peak Area $(\mathrm{S})$ & 455.06 & 0.12 & $\mathrm{~mm}^{2}$ & 0.0013 \\
\hline $\mathrm{C}(\mathrm{mmol} / \mathrm{mol})$ & 10.02 & & & \\
$u_{c}$ & 0.003 & & & \\
$\mathrm{C} x u_{c}(\mathrm{mmol} / \mathrm{mol})$ & 0.03 & & & \\
$U_{E x p}(\mathrm{mmol} / \mathrm{mol})$ & 0.052 & & & \\
$U_{E x p}(\%)$ & 0.52 & &
\end{tabular}


The uncertainty of mass of $\mathrm{CO}$ was estimated as explained above, while uncertainty of CRMs concentrations was calculated by dividing the expanded uncertainty given in each CRM certificate by 2 . Furthermore, uncertainty due to the peak area of each CRM and the peak area of the sample was calculated by dividing the standard deviation of the mean of 10 measurement results by $\sqrt{10}$. The combined standard uncertainty, $u_{c}$ was calculated using equation 18 for gas mixture (M4) as an explanatory example [20-25] and the results are given in Table 8. Meanwhile, uncertainty of the other two mixtures was estimated by the same approach and the results are given in Table 9 together with the mole fractions.

$$
u_{C}=C(\mathrm{~mol} / \mathrm{mol}) \sqrt{\left(\frac{u_{m_{C O}}}{m_{C O}}\right)^{2}+\left(\frac{u_{C R M}}{C_{C R M}}\right)^{2}+\left(\frac{u_{P A C R M}}{\text { Peak Area }}\right)^{2}+\left(\frac{u_{P A \text { Sample }}}{\text { Peak Area }}\right)^{2}}
$$

Table 9. The mole fractions of the three mixtures and their uncertainties

\begin{tabular}{l|ll|llll}
\hline Gas mixture & \multicolumn{2}{|c|}{ Gravimetry $(\mathbf{m m o l} / \mathbf{m o l})$} & \multicolumn{4}{c}{ GC-TCD $(\mathbf{m m o l} / \mathbf{m o l})$} \\
\hline & Mole fraction & $\boldsymbol{u}_{\boldsymbol{c}}$ & Mole fraction & $\boldsymbol{u}_{\boldsymbol{c}}$ & $\boldsymbol{U}_{\boldsymbol{E x p}}$ & $\boldsymbol{U} \%$ \\
\hline M2 & 4.99 & 0.005 & 4.98 & 0.013 & 0.026 & 0.52 \\
M3 & 7.49 & 0.01 & 7.50 & 0.019 & 0.038 & 0.51 \\
M4 & 10.00 & 0.01 & 10.00 & 0.026 & 0.052 & 0.52 \\
\hline
\end{tabular}

\subsection{Compatibility test of the Gravimetric and the GC-TCD Measurement Results}

The mole fractions of the three gas mixtures and their standard uncertainties shown in Table 9 were tested for compatibility according to the criterion in equation 19 as required by ISO 6142 and ISO 6143. They satisfy this criterion which confirms the good agreement between the gravimetric and the GCTCD measurements.

$$
\left|x_{\text {grav }}-x_{\text {anal }}\right| \leq 2 \sqrt{u\left(x_{\text {grav }}\right)^{2}+u\left(x_{\text {anal }}\right)^{2}}
$$

\subsection{Monitoring the Long Term Stability of the Prepared Gas Mixtures}

Stability of each gas mixture was monitored along 4 years. In each year, the $\mathrm{CO}$ mole fraction was measured 10 times in one run by the calibrated GC-TCD and the averages were plotted as shown in Figures 5, 6 and 7. In each of these figures, the solid line represents the certified $\mathrm{CO}$ mole fraction and the dashed lines represent the upper and lower limits of the expanded uncertainty. It can be noticed from the figures that the measured concentrations of the prepared gas mixtures are stable within their certified uncertainties along the four years. 


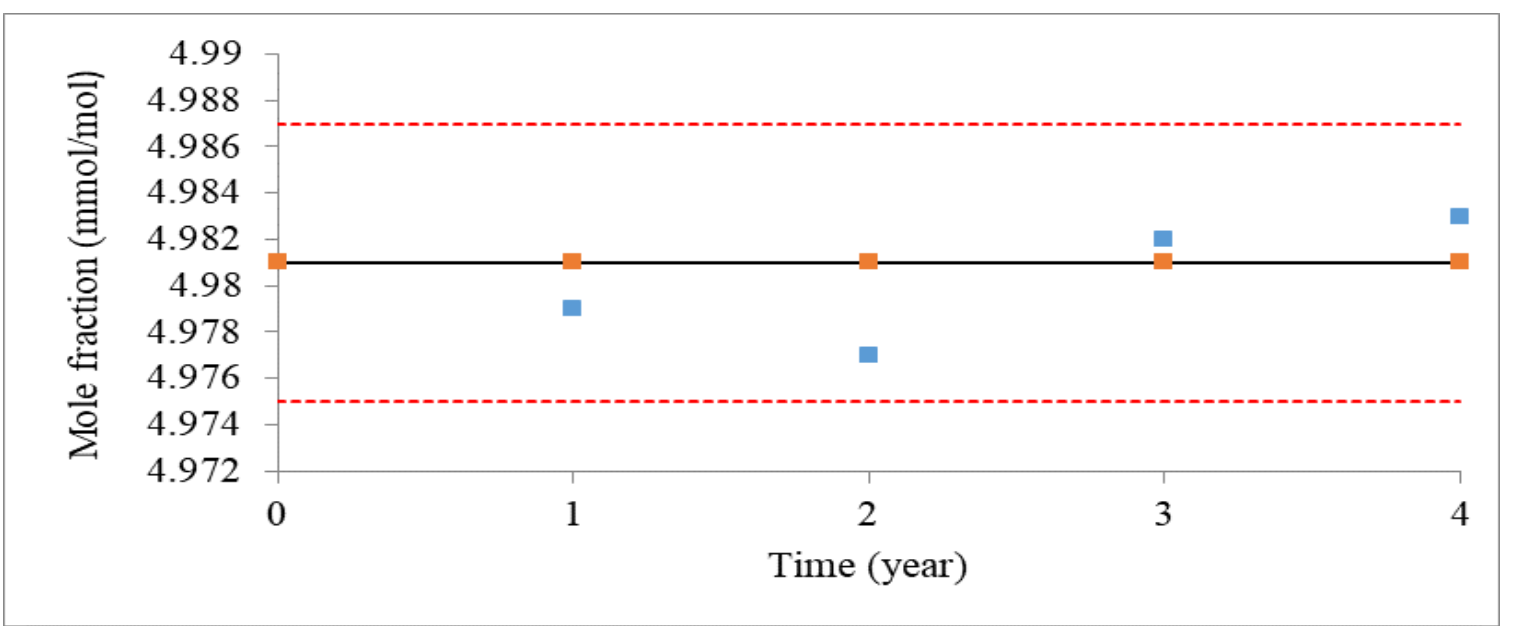

Figure 5. Long term stability chart of the gas mixture M2 $(4.98 \mathrm{mmol} / \mathrm{mol})$

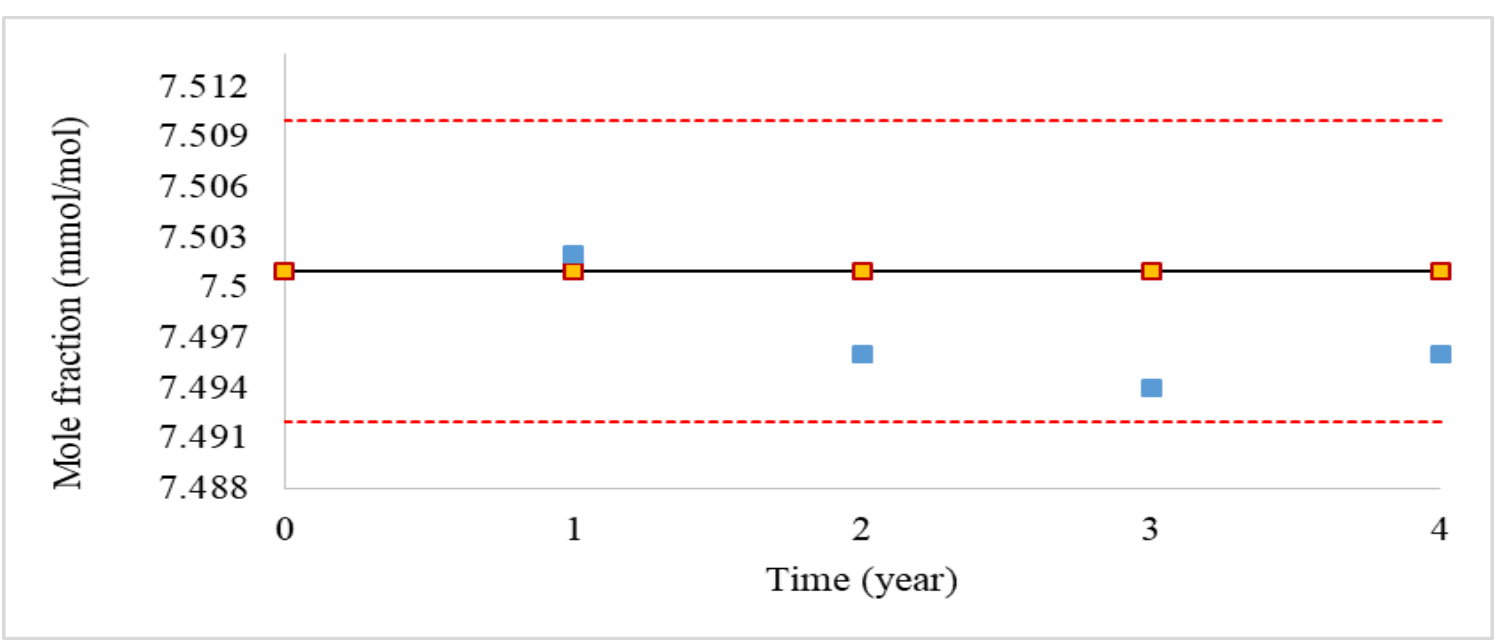

Figure 6. Long term stability chart of the gas mixture M3 (7.49 $\mathrm{mmol} / \mathrm{mol})$

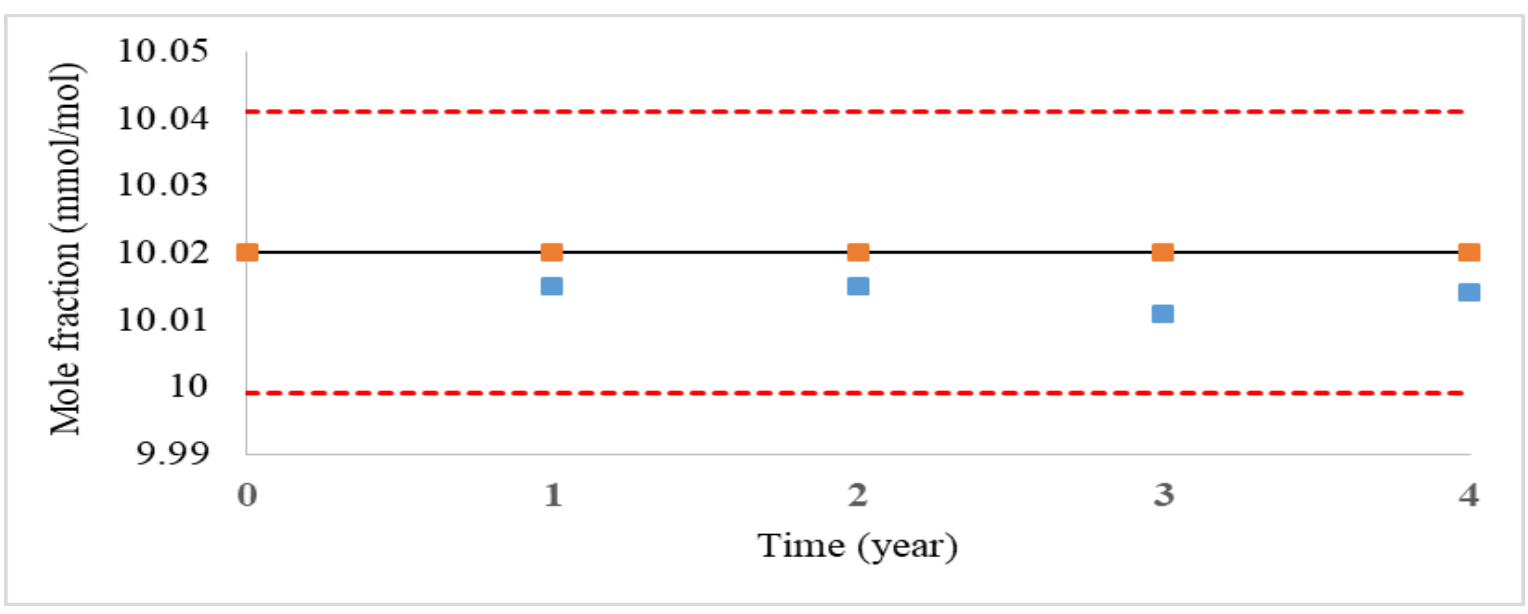

Figure 7. Long term stability chart of the gas mixture $\mathrm{M} 4(10 \mathrm{mmol} / \mathrm{mol})$ 


\section{Conclusion}

A certified reference material of $\mathrm{CO}$ gas in $\mathrm{N}_{2}$ was prepared gravimetrically in three mole fractions and was verified by GC-TCD and certified as 4.98, 7.5 and $10 \mathrm{mmol} / \mathrm{mol}$. The results of both methods and their standard uncertainties were found successfully compatible as required by ISO 6142 and ISO 6143. The relative expanded uncertainties of measurements were found $0.52 \%, 0.51 \%$ and $0.52 \%$ respectively. These uncertainties were found small enough which makes the CRM very useful for calibration of the $\mathrm{CO}$ emissions measuring equipment. The produced CRM showed very good long term stability along four years and this qualifies its certification for validity of five years. It can be used by gas testing laboratories for traceability provision to the SI units and as PT samples for accredited laboratories.

\section{ORCID}

Adel B. Shehata: $0000-0002-6818-4825$

Najjy H. Alyami 0000-0002-0981-7151

Abdullah S. AlOwaysi: 0000-0001-9177-843X

Abdulrahman. R. Alaskar: 0000-0002-9846-5265

\section{References}

[1] A. Dubey (2013). Studies on the air pollution around cement and lime factories, J. Environ. Earth Sci. 3, 191-194.

[2] H. Budiman and O. Zuas (2015). Validation of analytical method for the determination of high level carbon dioxde $\left(\mathrm{CO}_{2}\right)$ in nitrogen gas $\left(\mathrm{N}_{2}\right)$ matrix using gas chromatography thermal conductivity detector, Period. Tche Quim. 12, 7-16.

[3] O. Zuas, H. Budiman and M. R. Mulyana (2016). Temperature effect on thermal conductivity detector in gases (carbon dioxide, propane and carbon monoxide) analysis: a gas chromatography experimental study, J. Basic Appl. Res. Int. 13(4), 232-238.

[4] M. Rozhnov and O. Levbarg (2007). A way of establishing quality of measurements in gas analysisnational and international aspects, Accred. Qual. Assur. 12(8), 415-417.

[5] M. J. T. Milton, G. M. Vargha and A. S. Brown (2011). Gravimetric methods for the preparation of standard gas mixtures, Metrologia 48(5), R1-R9.

[6] E. A. D. Meane, M. Plassa, F. Rolle and M. Sega (2009). Metrological traceability in gas analysis at I.N.R.I.M gravimetric primary gas mixtures, Accred. Qual. Assur. 14, 607-611.

[7] E. De Leer (2006). The metrological infrastructure for gas analysis, Accred. Qual. Assur. 11, 175-181.

[8] R. C. Geib (2005). Calibration standard gases are key to reliable measurements. Specialty gas report. Montgomeryville: MathesonTri-Gas, Inc.

[9] M. J. T. Milton, F. Guenther, W. R. Miller and A. S. Brown (2006). Validation of the gravimetric values and uncertainties of independently prepared primary standard gas mixtures, Metrologia 43, L7-L10.

[10] L. Wang and Q. Han (2002). Primary reference materials and traceability chain for gas composition, Accred. Qual. Assur. 7, 217-219.

[11] ISO 6142 (E): Gas analysis-preparation calibration gas mixtures-gravimetric method (2001). 2nd Ed.

[12] H. Budiman, M. R. Mulyana and O. Zuas (2018). Preparation of calibration standard gas mixtures by primary gravimetric method: a case study on $960 \mu \mathrm{mol} / \mathrm{mol}$ of carbon dioxide in a nitrogen matrix, Engineer. Appl. Sci. Res. 45(3), 173-179.

[13] M. J. T. Milton, G. M. Vargha, and A. S. Brown (2011). Gravimetric methods for the preparation of standard gas mixtures, Metrologia 48(5), R1-R9.

[14] M. Buzoianu and H. Y. Aboul-enein (1997). The traceability of analytical measurements, Accred. Qual. Assur, 2, 11-17.

[15] G. Dube (2001). Metrology in chemistry - a public task Accred. Qual. Assur. 6, 3-7.

[16] H. Budiman, M. R. Mulyana and O. Zuas (2017). Gravimetric dilution of calibration gas mixtures $\left(\mathrm{CO}_{2}\right.$, $\mathrm{CO}$ and $\mathrm{CH}_{4}$ in He balance): toward their uncertainty estimation, AIP Conf. Proc. 1803, 1-11.

[17] M. E. Wieser and M. Berglund (2009). Atomic weights of the elements 2007 (IUPAC Technical Report), Pure Appl. Chem, 81(11), 2131-2156. 
[18] Eurachem/CITAC guide (2013): quantifying uncertainty in analytical measurement, $3^{\text {rd }}$ Edition.

[19] ISO 6143(E): Gas analysis-Comparison methods for determining and checking the composition of calibration gas mixtures (2001) 2nd ed.

[20] BIPM, IEC, IFCC, ISO, IUPAC, IUPAP, OIML (1993). Guide to the expression of uncertainty in measurement. $1^{\text {st }}$ ed.

[21] A. B. Shehata, M. S. Rizk, A. M. Farag and I. F. Tahoun (2014). Certification of three reference materials for a-and y-tocopherol in edible oils, Mapan, J. Chem. Soc. Ind. 29, 183-94.

[22] A. B. Shehata, M. S. Rizk, A. M. Farag and I. F. Tahoun (2015). Development of two reference materials for all trans-retinol, retinyl palmitate, $\alpha$ - and $\gamma$-tocopherols in milk powder and infant formula. J. Food Drug. Anal. 23, 82-92.

[23] A. B. Shehata, M. Gabr and M. A. Gab-Allah (2017). Development of crude oil reference material certified for the concentrations of sulfur, iron, nickel, vanadium and magnesium, Mapan, J. Chem. Soc. Ind. 32(2), 101-112.

[24] A. B. Shehata, M. S. Rizk, and E. A. Rend (2016). Certification of caffeine reference material purity by ultraviolet/visible spectrophotometry and high-performance liquid chromatography with diode-array detection as two independent analytical methods, J. Food Drug Anal. 24, 703-715.

[25] A. B. Shehata, A. R. Alaskar, M. A. Alrasheed, A. S. Alosaimi, F. A. Alkharraa and A. M. Alzahrani (2020). Certification of sodium benzoate solution reference material by HPLC-UV, LC-MS/MS and UVVIS-NIR spectrophotometry for food and drug analysis, J. Chem. Metrol. 14, 88-105.

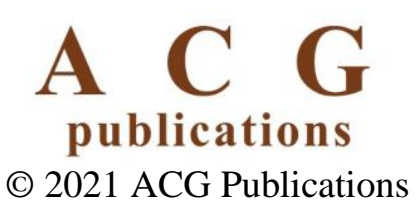

